\title{
Rediseño de un artefacto precinematográfico gracias a las nuevas tecnologías dentro de las artes visuales. Estudio de caso: Zoótropo 3D -Chopo cabecero
}

\section{Redesign of a precinematographic artefact thanks to new technologies within the visual arts. Case study: 3D Zoetrope - Black poplar pollard}

\author{
TIPO DE TRABAJO: Comunicación.
}

PALABRAS CLAVE

Artes visuales, chopo cabecero, imagen-movimiento, impresión 3D, precinematografía, zoótropo.

KEY WORDS

3D printing, black poplar pollard, moving picture, precinematography, visual arts, zoetrope.

RESUMEN

Antes de que los hermanos Lumière inventaran el cinematógrafo, se sucedieron toda una suerte de artefactos cuyo objetivo era producir en el espectador la ilusión de movimiento a partir de la observación de una sucesión de imágenes fijas. Hoy, tras la aparición de las nuevas tecnologías e inspirados por aquellos inventos, ha surgido una nueva tipología de aparatos, los zootropos 3D, los cuales para generar esta ilusión en vez de servirse de imágenes planas utilizan objetos tridimensionales. Si bien los primeros en los que se usó este procedimiento nacieron a mediados del siglo XIX, prácticamente en paralelo a aquellos que empleaban ilustraciones o fotografías, con la incorporación de técnicas como el escaneo y la impresión 3D han adquirido una nueva dimensión, planteando nuevos retos al tiempo que generan nuevos interrogantes.

En el siguiente trabajo se analiza brevemente esta trayectoria para acabar tratando una obra de producción propia, cuya intención es ofrecer una mirada crítica sobre nuestra relación tanto con la tecnología como con la imagen en la actualidad, partiendo de la reflexión sobre los propios dispositivos y procesos implicados en la construcción del artefacto. Los "fotogramas» necesarios para generar la animación se han obtenido, en este caso, reproduciendo en serie un fragmento de madera perteneciente a un tipo de árbol, el chopo cabecero, cuya particular morfología es el resultado de la combinación de las características de una especie vegetal populus nigra, y de la manipulación humana para su aprovechamiento con fines diversos. El resultado es una obra que pone en cuestión la largamente sostenida dicotomía naturaleza-cultura, así como la relación de antagonismo existente entre producción industrial y trabajo artesanal, a la vez que se ocupa de nociones como la de representación, para averiguar qué ha ocurrido tras la crisis que de ella se ha planteado desde perspectivas muy diferentes.

\section{ABSTRACT}

Before the Lumière brothers invented the cinematograph, a whole series of artefacts followed one another, the objective of which was to produce in the spectator the illusion of movement from the observation of a succession of still images. Today, after the emergence of new technologies and inspired by those inventions, a new typology of devices has emerged, the 3D zoetropes, which use three-dimensional objects to generate this illusion instead of using pictures. Although the first ones in which this procedure was used were born in the middle of the XIX century, practically in parallel to those that used illustrations or photographs, with the 
incorporation of techniques such as 3D scanning and 3D printing, they have acquired a new dimension, posing new challenges while generating new questions.

In the following work we briefly analyse this trajectory to end up dealing with a work of own production, whose intention is to offer a critical perspective on our relationship both with technology and with the image nowadays, starting from the reflection on the own devices and processes involved in the construction of the artifact. The "frames» necessary to generate the animation have been obtained, in this case, reproducing in series a fragment of wood belonging to a type of tree, the black poplar pollard, whose peculiar morphology is the result of the combination of the characteristics of a plant species -populus nigra, and human manipulation for its use for various purposes. The result is a work that calls into question the long-held nature-culture dichotomy, as well as the existing antagonistic relationship between industrial production and craftwork, while dealing with notions such as representation, to find out what happened after its crisis as has arisen from very different perspectives.

\section{INTRODUCCIÓN}

El siguiente trabajo tratará de abordar, desde una perspectiva de investigación basada en la práctica artística, las implicaciones teóricas y filosóficas que pueden llegar a surgir fruto del rediseño y producción de un artefacto englobado dentro de la categoría de inventos "precine», el zoótropo, como resultado del uso de las nuevas tecnologías y en función de la especificidad de algunos de los materiales empleados en su construcción.

\section{METODOLOGÍA}

En un primer punto trataré de localizar el momento exacto del nacimiento del dispositivo desde el que se ha partido, ubicándolo en su contexto histórico, para tras un breve análisis de este, dar un salto de más de un siglo y pasar a ver algunas actualizaciones que del mismo se han llevado a cabo en la actualidad. Se expondrá una pequeña selección de zoótropos -representativa en su conjunto del aparentemente renovado interés que estos artefactos despiertan hoy- extraídos en su mayor parte de un contexto artístico y que presentan como se verá una particularidad: la utilización de figuras tridimensionales.

Finalmente pasaré al estudio del caso en cuestión, una obra de producción propia consistente en un zootropo 3D de grandes dimensiones. Por el tipo de materiales empleados, tanto a nivel estructural como en el caso de las piezas destinadas a la generación de la animación, se podría argumentar -siguiendo en este sentido el pensamiento desplegado por W.T.J. Mitchell (2009) en base a la noción de metaimagen- que el aparato en cuestión de algún modo se «pliega» sobre sí mismo, para reflexionar sobre su propia naturaleza, en tanto artefacto que trabaja a partir de la serie-encabalgamiento-superposición de términos como los de imagenrepresentación-reproducción-realidad. La obra establece además un puente entre trabajo artesanal y nuevas tecnologías a través del uso de un elemento natural en el que todas estas categorías entran en juego, generando una serie de tensiones, fricciones, fuerzas de atracción y resistencia que nos invitan a indagar sobre algunas categorías y conceptos clave en una sociedad postindustrial y e hipermediatizada como la nuestra.

\section{DESARROLLO}

\section{El zoótropo: invención y contexto}

Previamente a que los hermanos Lumière inventaran el cinematógrafo, se sucedieron toda una serie de dispositivos ópticos cuya intención era generar la ilusión de movimiento a partir de la observación de una secuencia de imágenes fijas, y que han llegado hasta nuestros días bajo la denominación de artefactos "precinematográficos». La categoría "precine» no carece sin embargo de controversia, y diversos autores han criticado esta habitual catalogación que atribuyen a una visión teleológica de la historia del cine, que se orienta en función de la aparición de un único medio y bajo la cual quedan subsumidos todos esos relatos "otros», reclamando un «marco espectacular, técnico y social más amplio» (Frutos, 2010, p. 176).

La mayor parte de estos aparatos surgieron a lo largo del siglo XIX, momento en que consuma la revolución industrial, y caracterizado por la experimentación mecánica en diversos ámbitos -trabajo, hogar, diversión- (Talens y Zunzunegui, coords., 1998, p. 39), de la mano de los últimos avances técnicos y descubrimientos científicos. En el ámbito mediático, eclosiona un universo caracterizado por la «trápala» (Alonso, 1995, p.6, citado en Frutos, 2010, p. 176), término acuñado para designar un cúmulo heterogéneo de 
manifestaciones que incluiría entre otras "diversiones populares" como la magia, el circo, los gabinetes de figuras de cera y autómatas, los cuadros vivos, los teatros de sombras, los espectáculos aerostáticos, las iluminaciones, la pirotecnia, las estampas, las aleluyas, los almanaques, las revistas ilustradas o las obras de divulgación científica» (Frutos, 2010, p. 177).

En este contexto nace el zoótropo, un invento del matemático inglés William George Horner que daría a conocer en 1834 con el nombre de daedaleum, y cuya su versión más conocida, la que ha llegado mayoritariamente hasta nosotros, corresponde a William Ensign Lincoln y la Milton Bradley Company (Herbert, s.f.). El zoótropo fue utilizado principalmente con dibujos e ilustraciones, pero uno de los pioneros en la investigación cronofotográfica emplearía este aparato de un modo especialmente interesante para el tema que aquí nos ocupa: el médico, fisiólogo e investigador francés Étienne-Jules Marey. Inventor del fusil fotográfico, inspirado en el revolver fotográfico de Pierre-Jules-César Jansen, representaría junto al astrónomo francés, una de las dos vertientes del interés por la imagen-movimiento, más cercana a la motivación científica y pedagógica. La cronofotografía entonces podría diferenciarse de la cinematografía por el tipo de disposición comunicativa que presentaba hacia el medio, más orientada en este último caso a unos fines comerciales y de espectáculo (Frutos, 2010, pp. 100-104) -doble aproximación que me parecía interesante constatar aquí ya que como se verá, la obra objeto de este texto de algún modo recoge o aúna el espíritu de ambas perspectivas. En 1887, Marey partiendo de sus cronofotografías de análisis del movimiento, modeló en primer lugar unas pequeñas esculturas intentando reproducir en volumen las distintas fases de la trayectoria del vuelo de un ave, que dispondría posteriormente en círculo en el interior del tambor del que sería uno de los primeros -si no el primero- zoótropos con figuras tridimensionales. ${ }^{1}$

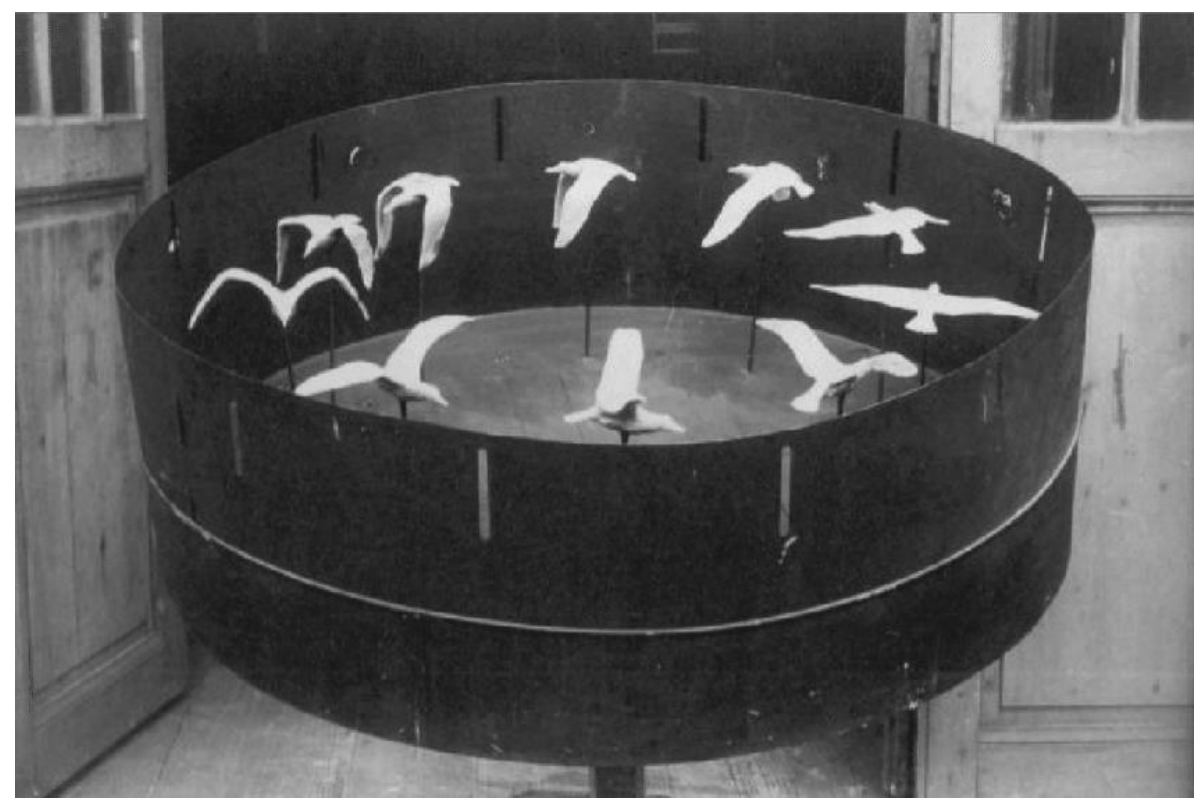

Figura 1. Zoótropo con en el que Marey trató de recrear el vuelo de una gaviota mediante la sucesión de 10 pequeñas figuras tridimensionales basadas en sus cronofotografías, 1887. Fuente: Wikimedia Commons. https://en.wikipedia.org/wiki/File:Murey.jpg

\section{Zoótropos 3D en la actualidad}

En tiempos recientes y particularmente dentro de contextos artísticos, este artefacto ha sido recuperado como una herramienta que posibilita el desarrollo de nuevas estrategias de creación. En especial -y es el caso en el que aquí nos vamos a centrar- han tenido una gran repercusión aquellos en los que se ha implementado el uso de objetos tridimensionales.

Un caso interesante por encontrase todavía a medio camino entre la utilización de imágenes planas y el uso de reproducciones con volumen es el del artista y animador profesional Eric Dyer. ${ }^{2}$ La peculiaridad fundamental de sus zoótropos es que para poder percibir

\footnotetext{
${ }^{1}$ En The National Science and Media Museum, Bradford se puede encontrar actualmente una réplica del mismo: https://collection.sciencemuseum.org.uk/objects/co18348/model-of-zoetrope-with-solid-figures-of-birds-in-flight-zoetrope

${ }^{2}$ Puede verse el siguiente TED Talk en el que este creador expone su metodología de trabajo: https://www.youtube.com/watch?v= B9A3J70IPQ
} 
el movimiento de sus personajes necesitan ser observados a través de una videocámara. La captura de 25 imágenes por segundo del dispositivo suple en este caso la función de las ranuras del tambor de un zoótropo tradicional destinadas a generar el efecto estroboscópico necesario para percibir la secuencia animada. Algunos zoótropos que sí emplean ya propiamente objetos tridimensionales, son los trabajos de Peter Hudson. ${ }^{3}$ Estas enormes estructuras, surgidas en la confluencia de arte y espectáculo, combinan el movimiento en bucle de las figuras con algo que será fundamental en la redefinición de este tipo de artefactos: el uso de luces estroboscópicas. Aquí el destello de milésimas de segundo producido por la lámpara permite que obtengamos una imagen nítida de cada una de las «escenas-fotogramas» que componen la secuencia, de modo que al sucederse generan en el espectador la ilusión de movimiento.

Con la aparición de las nuevas tecnologías y el control y precisión que permiten herramientas como el escaneo, el modelado y la impresión 3D, así como el uso de diferentes softwares, lenguajes de programación y sistemas embebidos, el panorama de los zoótropos 3D ha experimentado un resurgir, y diversos artistas han aprovechado estas herramientas para el desarrollo de sus propuestas. Un buen ejemplo es el del conocido artista británico Mat Collishaw, que desde hace algunos años ha estado utilizando el zoótropo tridimensional dentro de su producción artística. ${ }^{4}$ Una pieza que ha tenido especial difusión, quizá por tratarse uno de los primeros zoótropos de gran formato impreso enteramente en 3D, es el titulado All things fall, inspirado en el episodio bíblico de la matanza de los inocentes. Existen también numerosos ejemplos de proyectos más modestos en cuanto a escala y recursos, pero igual de interesantes que los anteriores, ya que pueden ayudarnos a hacernos una idea de los diferentes acercamientos a este medio y del abanico de posibilidades que abre. Uno de ellos es el caso del japonés Akinori Goto, cuyas propuestas presentan la particularidad de que su descomposición del movimiento no se materializa en figuras aisladas, si no en la forma de una malla impresa en 3D. Ese volumen que en su conjunto correspondería a la estela total del tránsito en círculo que una figura dibujaría en el espacio, al ser intersectado por un haz de luz lineal, muestra la figura o las figuras en movimiento. Este ejemplo supone una transformación sustancial del diseño del zootropo original, como también es el caso de las esculturas estroboscópicas de John Edmark, en un nuevo giro vinculado esta vez a la geometría fractal. Otro ejemplo es el del artista vietnamita Witaya Junma, que trabaja con este y otros dispositivos que utilizan los mismo principios mecánicos y físicos, para por ejemplo "animar» el estampado de unas alfombras colocadas en unos rodillos que las hacen girar en bucle. O finalmente, en la encrucijada entre arte, diseño, ciencia y tecnología podríamos destacar la propuesta del estudio Nervous System, ${ }^{5}$ el cual ha fabricado varios zoótropos que ilustran diferentes procesos naturales de crecimiento a partir de su simulación mediante algoritmos y su posterior diseño e impresión en 3D.

Estos son solo algunos ejemplos de dan cuenta de la nueva vida que parece tener este artefacto, que va de la mano de una dinámica más general, en la que otros muchos de esos dispositivos "precine» se están recuperando y rediseñando en multitud de contextos, educativos, artísticos, ${ }^{6}$ científicos o publicitarios. ${ }^{7}$

\section{Zootropo 3D - Chopo Cabecero}

\subsection{Origen del proyecto}

En un primer momento, el interés por la utilización de tecnologías como el escaneo y la impresión 3D vino asociado a la intención de trabajar con la iteración -en un proceso paulatino de registro y reproducción de la última copia que se va generando en una serie, algo que había explorado en trabajos fotográficos previos, para ver a donde conducía teniendo en cuenta los nuevos condicionantes de tridimensionalidad. El resultado es la obra Tronco-madera (tecnoentropía) de 2016, desarrollada durante una residencia artística en la Fundación BilbaoArte. El siguiente paso, la idea de poder ver esa serie animada, surgió ya en aquel entonces al tiempo en que llegaba a la finalización de la obra, algo que pude recuperar en 2018 gracias a que el proyecto fue seleccionado en la beca de producción César e-fluxus a desarrollar en Etopia, Centro de Arte y tecnología de Zaragoza.

Si bien en ese primer trabajo el objetivo fue intentar establecer de alguna manera un paralelismo entre diferentes procesos entrópicos, esto es, detener el asociado a los procesos naturales para continuarlo en un entorno digital, esta nueva propuesta requería un nuevo paso a nivel conceptual. Así, el proyecto presentado a la convocatoria, del que la pieza del zootropo formaba parte,

\footnotetext{
${ }^{3}$ Pueden estas obras en su web: https://www.hudzo.com/

${ }^{4}$ En la web del artista figura este junto al resto de zootropos que ha producido en los últimos años: https://matcollishaw.com/

${ }^{5}$ Para ampliar información visitar: https://n-e-r-v-o-u-s.com/

${ }^{6}$ Por mencionar sólo un ejemplo cercano, se podría destacar el proyecto del colectivo zaragozano Opn Studio, el cual creó una gran instalación interactiva en la que una serie de engranajes acababan poniendo en funcionamiento un zoopraxiscopio que proyectaba una secuencia animada en el techo de la sala de exposiciones. Para más info: http://opnstudio.com/give-my-creation-life/
}

${ }^{7}$ Otro conocido ejemplo que pudo verse en España sería el construido por el estudio de animación Pixar conmemorando su 25 aniversario. 
partía de un interés inicial sobre la madera en tanto material que nos permite afrontar de un modo especialmente significativo la relación del ser humano con el medio natural, por un lado, y con el uso de herramientas y de la técnica por el otro. Tras estar barajando diferentes posibilidades llegué finalmente a la conclusión de que el chopo cabecero era la elección idónea ya que condensaba todos estos factores de tal manera que se manifestaban en su propia fisionomía.

\section{2. El álamo trasmocho o chopo cabecero}

Actualmente en la cordillera ibérica, la zona con mayor concentración de este tipo de árbol en la península, se estima que existe un total de cien mil chopos cabeceros. Antaño ampliamente extendidos por los espacios rivereños de un área que comprende la mayor parte de la provincia de Teruel y algunas zonas aisladas de la de Zaragoza, su población se ha visto reducida de manera drástica en las últimas décadas por la desaparición de los modos de vida y usos tradicionales vinculados a su cultivo y aprovechamiento (Herrero y Lorén, 2013). El tipo de masa forestal a que da lugar cuenta con un gran valor ecológico, paisajístico y cultural, un patrimonio etnográfico que ha hecho que en los últimos años se haya creado todo un movimiento que trabaja por su conservación y reconocimiento tanto por parte de la ciudadanía como de las instituciones. ${ }^{8}$

Un ejemplar de chopo cabecero maduro muestra una peculiar morfología como resultado de la combinación de las características de una especie en concreto, el "populus nigra» o álamo negro, y de su manipulación por parte del ser humano, en este caso un tipo particular de poda destinada a la obtención de forraje para el ganado y de madera para leña y construcción. Se trata por lo general de un árbol con un gran tronco que presenta un engrosamiento en la parte superior, denominado cabeza o toza, como resultado del proceso de escamonda realizado siempre en la misma zona. El corte periódico de las principales ramas siempre a la misma altura hace que el árbol vaya generando este engrosamiento como defensa, además de como soporte para las nuevas ramas que generan una gran tensión, mayor cuanto más longevo es el árbol (Herrero y Lorén, 2013, pp. 30-31).
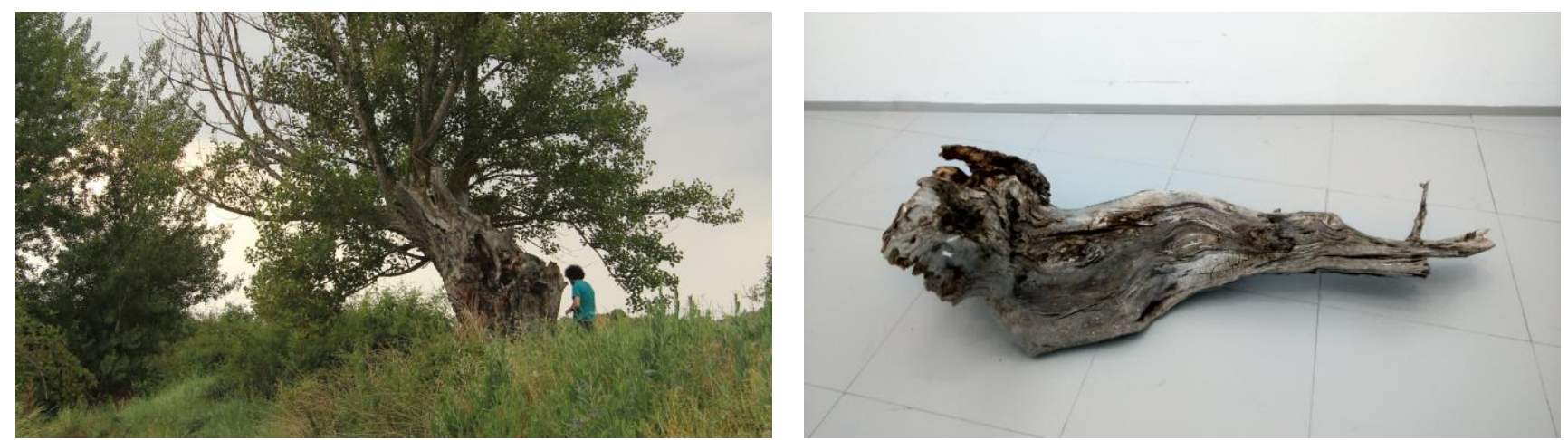

Figura 2. a) cuenca alta del río Huerva donde se pude observar un ejemplar maduro de chopo cabecero. b) fragmento del tronco de un chopo cabecero caído, del que extraería el fragmento final para realizar la serie de impresiones 3D.

El interés para el proyecto radicaría por lo tanto en que ese pequeño fragmento de leña retorcida elegido para la pieza, esa aparentemente caprichosa forma, vinculaba la reflexión abstracta a un hábitat concreto, a unas prácticas y unos modos de vida configuradores del entorno, conduciendo la reflexión hacia una nueva capa semántica en la que se aborda la relación entre naturaleza y cultura, así como entre producción industrial y trabajo artesanal, desde un enfoque que pone en cuestión posicionamientos dicotómicos, entendiendo el paisaje como algo en lo que confluye lo natural y lo humano, y que contribuye desde la visualidad a la configuración de una determinada identidad.

\footnotetext{
${ }^{8}$ Véase la página dedicada al chopo cabecero en la web del Centro de Estudios del Jiloca: http://xiloca.org/chopocabecero/. También, un buen ejemplo de ello es el congreso internacional de árboles trasmochos que tendrá lugar en marzo de este año en las localidades turolenses de Galve y Aguilar de Alfambra, organizado por el Parque Cultural del Chopo cabecero del Alto Alfambra y apoyado por el Gobierno de Aragón, en el que se darán cita expertos en este ámbito de diferentes países con el objetivo de reivindicar el valor de estos árboles vinculado a la cultura campesina, y que sea reconocido por parte de la UNESCO como Patrimonio Cultural Inmaterial. Más información en: https://parquechopocabecero.com/congresointernacional-arboles-trasmochos-un-patrimonio-cultural/y https://www.diariodeteruel.es/noticia.asp?notid=1012311
} 


\section{3. Obra final}

En base a lo visto, el objetivo ha sido el de generar una serie en la que mediante el escaneo e impresión sucesiva de los modelos 3D realizados en PLA-madera- que se han obtenido a partir del tronco original, percibamos, gracias a las alteraciones e imperfecciones resultantes del mismo proceso digital y de la colocación en loop de todos ellos, una secuencia animada. El resultado es un zoótropo de carácter escultórico y escala humana que presenta dos estados: uno en reposo, en el que se puede observar toda la serie con detenimiento; y una secuencia en la que el plato gira a diferentes velocidades, mostrando la animación de las piezas que se quedan en su lugar, avanzan o retroceden lentamente en relación al sentido de giro. ${ }^{9}$ Una secuencia que se activa cuando el visitante entra en la sala y se aproxima a la obra -con lo que más que interactiva podría decirse que es reactiva.
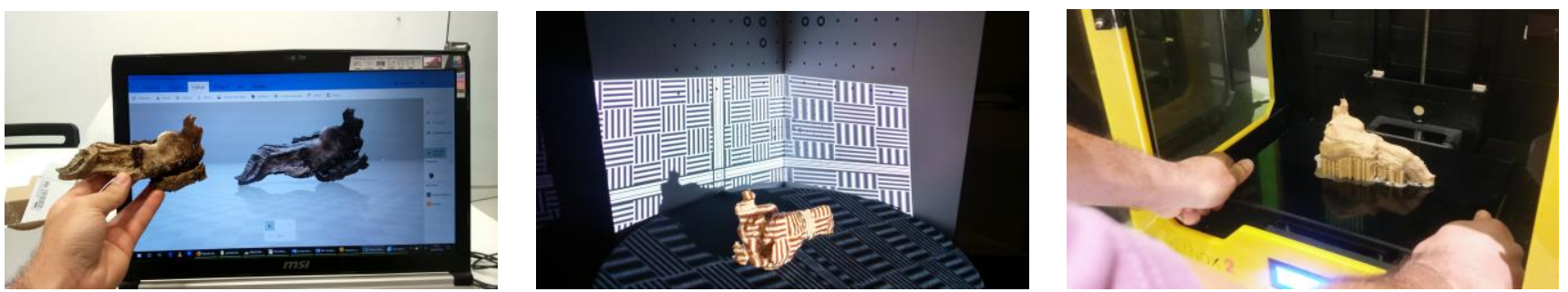

Figura 3. Proceso de escaneo, modelado e impresión 3D de las diferentes copias a partir del fragmento de chopo original.
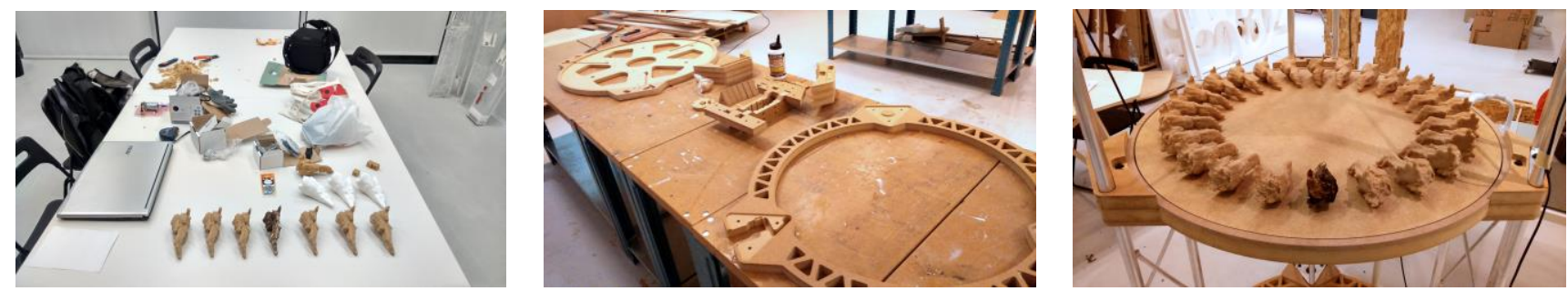

Figura 4. Proceso de fabricación y montaje de la estructura del zoótropo, y posterior disposición de las impresiones 3D en el plato central para comenzar con las pruebas de sincronización de las luces con el giro del motor.

\section{CONCLUSIONES}

Al entrar en la sala, observamos una estructura con un disco central sobre el que reposan una serie de 24 piezas pequeñas, impresas en 3D, a excepción de una de ellas que parece ser un trozo de madera real, así como el original del que ha partido toda la serie. Cada unidad muestra unas pequeñas diferencias con respecto a las de sus dos costados. Tras unos instantes, la luz se corta, para encenderse después con una cadencia que apenas hace perceptible el parpadeo, y en el plato en vez de observar 24 piezas estáticas, observamos ese mismo número de objetos pero que ahora se muestran animados, con una cadencia leve de dilatación y contracción. Un movimiento sutil y repetitivo, como el pálpito de un corazón, como la respiración. Un ritmo, un movimiento cíclico, como las estaciones, como las mareas o como el giro de la tierra, que nos inserta en una temporalidad diferente a la linealidad a la que nos tiene acostumbrado el relato del cine convencional. Distinto a la lógica teleológica del proyecto moderno y del progreso $-\mathrm{y}$ de la historia del cine, como hemos visto- y que de alguna manera ya reivindicaban como propia aquellos artefactos de la época victoriana en plena industrialización.

\footnotetext{
${ }^{9}$ Para el trabajo de mecánica y especialmente para las cuestiones de electrónica se contó con el asesoramiento técnico de David Orús, que ha estado colaborando durante los últimos meses en este proyecto.
} 


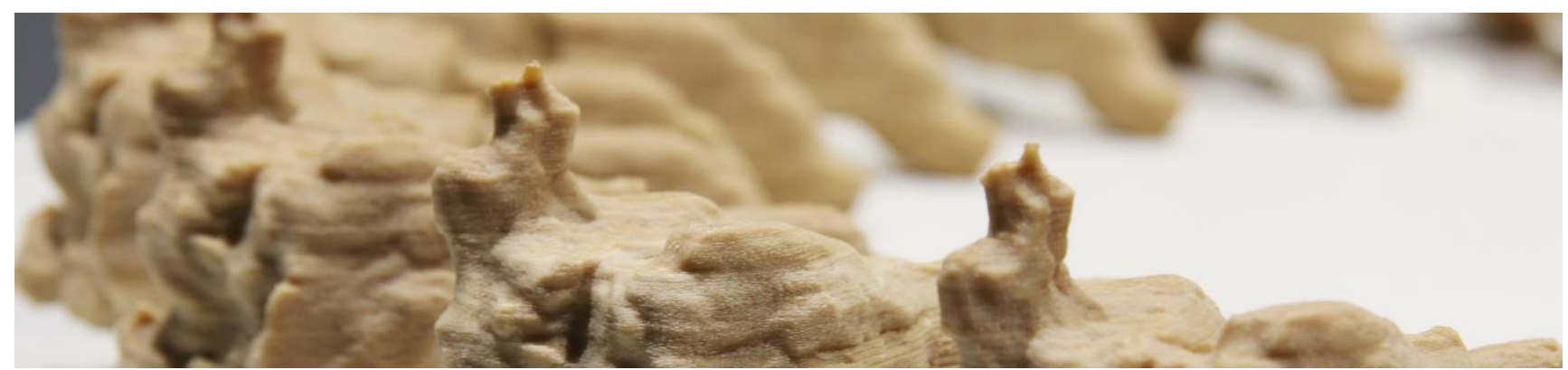

Figura 5. Zoótropo 3D-Chopo cabecero, 2019. Vista de detalle.

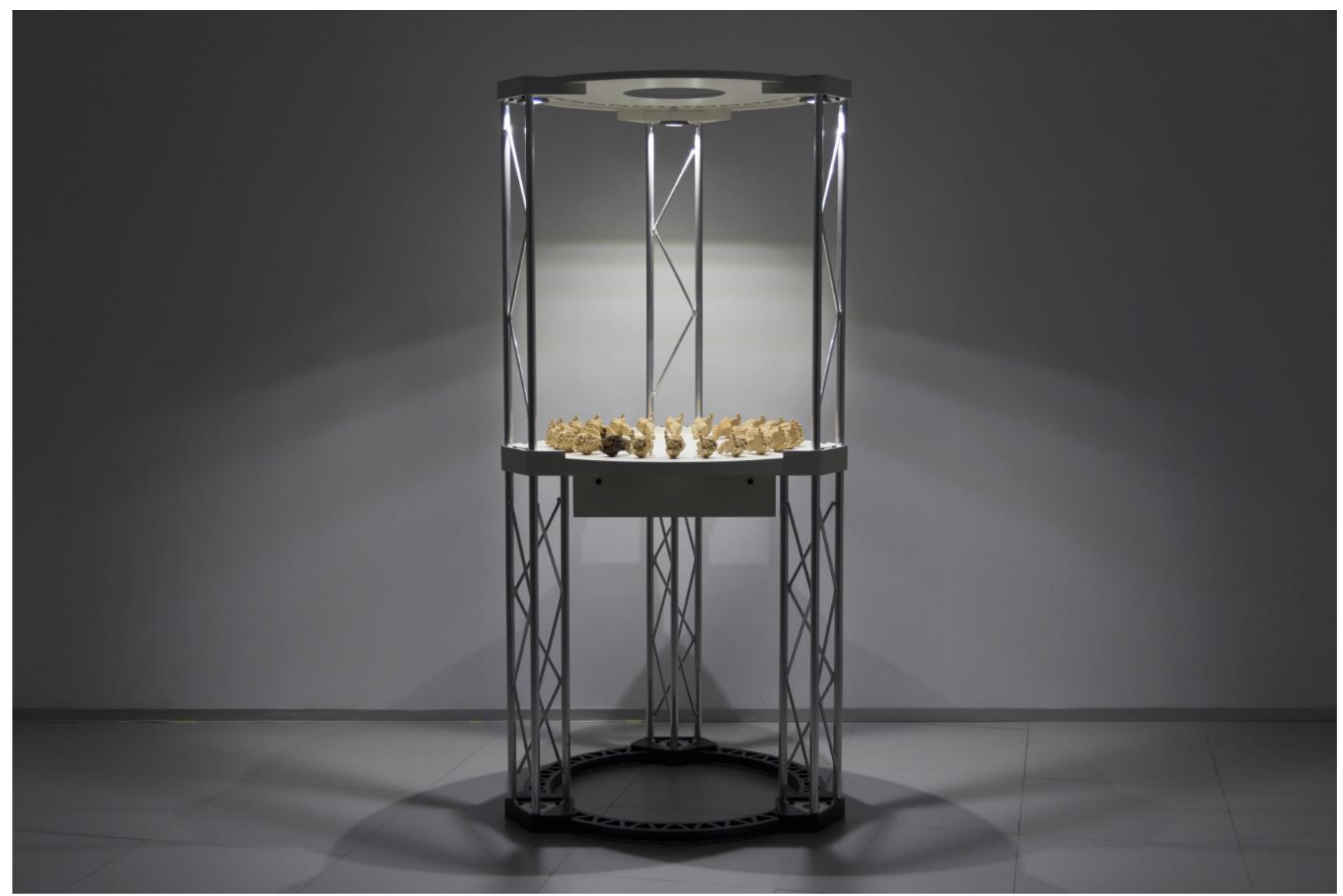

Figura 6. Zoótropo 3D-Chopo cabecero, 2019. Vista de instalación.

Sin embargo, también hay algo paradójico, ya que al substituir el proceso de manipulación humana con métodos artesanales por otro en el que se emplean las nuevas tecnologías, al cambiar el ciclo de poda y rebrote por uno de iteración digital, en la seriación también parece emerger lo maquínico en tanto siniestro -un poco a la manera de Metrópolis. Así, al observar la pieza, se da un tipo de extrañamiento -noción acuñada por Victor Sklovsky (2012) en 1917, vinculada al formalismo ruso y originariamente común a todo arte- que cobra aquí una fuerza renovada, fruto de la combinación de dos posibles diferentes dimensiones de esta experiencia. Se aúna pues un tipo de extrañeza vinculada a lo óptico, esa sorpresa de lo visualmente impactante y nuevo, con ese otro tipo de desasosiego que de algún modo pone en crisis al sujeto, presente en el pensamiento de otros autores con fórmulas como inquietar el ver (Huberman, 1997), vinculadas a su vez al pensamiento lacaniano -como en el planteamiento de Foster (2001). 

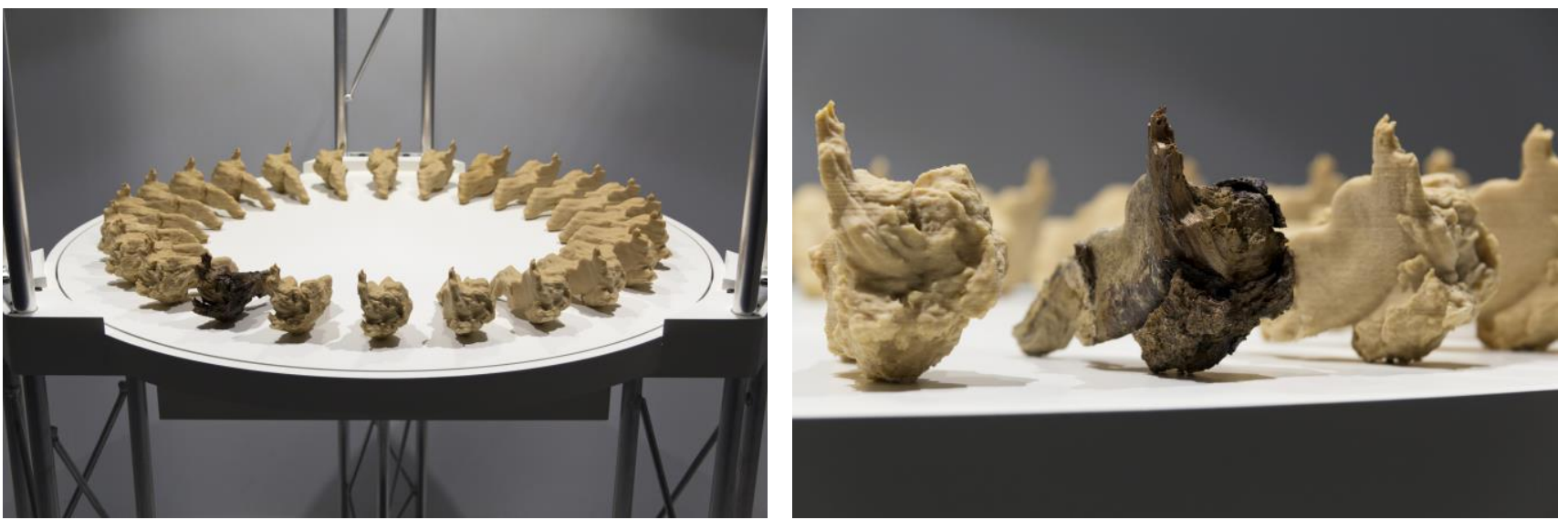

Figura 7. Zoótropo 3D -Chopo cabecero, 2019. Vista de detalle.

La obra ya en su totalidad, como artilugio o máquina, aúna de algún modo esas dos tendencias vistas, vinculadas por un lado el espectáculo y por el otro al experimento científico. Existe el análisis y trabajo minucioso, la utilización de dispositivos como la luz estroboscópica que se emplean en un contexto industrial para la identificación de defectos en la producción de piezas en cadena. Y a su vez cuenta con elementos que lo acercan a un contexto de exhibición mediática, algo que actualiza en su propia estructura empleando materiales asociados a los grandes escenarios y espectáculos de nuestro tiempo. Se instala de este modo en un espacio liminal, en el que apunta a los diferentes posicionamientos que respecto a las imágenes se han planteado desde el pensamiento actual. Se instala de lleno en esa brecha abierta por la denominada crisis de la representación, en la que las imágenes reclaman un nuevo estatus como presencia, que habla de su performatividad (Fernández, 2012) y de su capacidad de agencia, ${ }^{10}$ de su poder para hacernos hacer cosas. Cabría entonces recuperar la ilusión (Baudrillard, 2006), en el sentido de recuperar la distancia en una realidad integral (Baudrillard, 199) en la que la imagen y su objeto se funden y se confunden; o por el contrario, cabría destinar nuestras energías en reubicar la imagen en el cruce entre lo estético y lo político (Martínez, 2016, p. 107), en lo que ha sido denominado por alguno autores como un régimen esópico de hipervisión administrada (Brea, 2010), poniendo el énfasis en la desigual distribución de lo sensible (Rancière, 2008). Esta pieza actualiza todas estas problemáticas ${ }^{11}$ y se sitúa, toma un lugar, de manera física, táctil, como imagen que posibilita que el pensamiento siga, que la indagación se abra paso. Toma posición al obligarnos a preguntarnos sobre qué ocurre cuando aquello que se nos da a la percepción incluye a su vez al objeto y a su copia, si es que se puede ya hablar en estos términos. Cuando al mismo tiempo lo deslocaliza, lo disloca. Cuando al incluir la dimensión performativa y temporal en acto, la imagen explota y parece fundirse y reclamar definitivamente un espacio en lo real.

\section{FUENTES REFERENCIALES}

Baudrillard, J. (2006). La agonía del poder. Madrid: Círculo de Bellas Artes.

Baudrillard, J. (2007). El complot del arte: ilusión y desilusión estéticas. Buenos Aires: Amorrortu.

Brea, J. (2010). Las tres eras de la imagen. Imagen-materia, film, e-image. Madrid: Akal.

Didi-Huberman, G. (1997). Lo que vemos, lo que nos mira. Buenos Aires: Manantial.

Didi-Huberman, G., Jaar, A., Pollock, G., Rancière, J., Schweizer, N. (2008). La Política de las imágenes. Santiago de Chile: Metales Pesados.

Fernández, A. (2012). Usos performativos de las imágenes. Re-visiones, 2. Recuperado de http://www.re-visiones.net/index.php/REVISIONES/article/viewFile/141/153

\footnotetext{
10 Un buen ejemplo de la actualidad de estos temas en las discusiones y debates sobre estética y filosofía de la imagen es la actividad que viene desarrollando desde hace varios años del grupo de investigación Estética y Filosofía de la imagen de la Universidad de Zaragoza, dirigido por Ana García Varas.

${ }^{11}$ Las reflexiones que aquí figuran no tienen carácter definitivo, sino que habrán de ser exploradas con mayor profundidad, ampliadas o redefinidas conforme se avance en la investigación ya que este escrito, o parte de lo visto en él, idealmente formará parte de la tesis doctoral en la que me encuentro trabajando.
} 
Foster, H. (2001). El retorno de lo real: la vanguardia a finales de siglo. Madrid: Akal.

Frutos, F. J. (2010). Los ecos de una lámpara maravillosa: la linterna mágica en su contexto mediático. Salamanca: Universidad de Salamanca.

García, A. (ed.) (2011). Filosofía de la imagen. Salamanca: Universidad de Salamanca.

Gómez, A. (2002). Arqueología de la imagen fílmica: de los orígenes al nacimiento de la fotografía. Madrid: Archiviana.

Gubern, R. (1982). Historia del cine (vol. 1) (3a ed.). Barcelona: Lumen.

Herbert, S. (s.f.). From Daedaleum to Zoetrope. Recuperado de https://www.stephenherbert.co.uk/wheelZOETROPEpart1.htm

Herrero, F. y Jaime, C. (2007). El chopo cabecero en el sur de Aragón: la identidad de un paisaje. Calamocha: Centro de Estudios del Jiloca.

Martínez, S. (2016). La cultura visual contemporánea y la cuestión de la materialidad: Imágenes, mediaciones, figuralidad. Escritura e imagen, 12, 93-111. https://doi.org/10.5209/ESIM.54032

Mitchell, W. J. T. (2009). Teoría de la imagen. Ensayos sobre representación verbal y visual. Madrid: Akal.

Rancière, J. (2010). El espectador emancipado. Buenos aires: Manantial.

Shklovski, V. (2012). El arte como artificio. En Todorov, T. (ed.). Teoría de la literatura de los formalistas rusos. Madrid: Biblioteca Nueva.

Talens, J. y Zunzunegui, J. (coords.) (1998). Historia general del cine (vol. 1). Madrid: Cátedra.

Virilio, P. (1998). La Máquina de visión. Madrid: Cátedra.

Zubiaur, F. J. (1999). Historia del cine y de otros medios audiovisuales. Pamplona: EUNSA. 